are now employed as policemen to patrol it. Many passengers now leave their rifles at home, showing that law and order is being established. Col. Barnes pointed out the great advantages that would accrue to the railways if the motor industry were developed so as to feed and not to compete with them. Mechanical transport in India has received little encouragement from the Government. It has been mainly regarded as a source of extra revenue and heavily taxed. Despite this, it has flourished and is now one of the principal industries in the country. There can be little doubt that if it is encouraged, there will be a great future in India for mechanical transport.

\section{Meteor Crater, Arizona}

THE Meccano Magazine for March contains an illustrated article on this unique formation. The photographs give a vivid idea of the force of the impact, which shattered the rocks, and forced up great blocks of limestone. Mr. D. M. Barringer has for many years been making efforts to discover the meteor itself. Two vertical shafts were sunk near the centre of the crater, but there was no success, and the work was impeded by the influx of water, which turned the powdered rock-flour into a quicksand. Eventually experiments on the impact of projectiles led to the conclusion that oblique impacts give a nearly circular.depression: Mr. Barringer had at first assumed that the meteor would lie under the centre of the pit, but further examination of the shattered rocks suggested that it had come from the north and was likely to lie under the southern edge of the pit. A shaft is now being sunk in undisturbed soil a quarter of a mile to the south of the pit; this will be continued to a depth of some $1,400 \mathrm{ft}$., and then a horizontal shaft will be run to the north, in the hope of encountering the meteor, which may be either a single great metal mass (in which case it is estimated to weigh some ten million tons) or a compact swarm of smaller masses. There is still some trouble from water, but it is hoped to overcome this by surrounding the shaft with reinforced concrete. Mr. Barringer has now been carrying on his arduous exploration for many years, and certainly deserves success. The article makes some estimates as to the date of the impact; it cannot be less than seven centuries ago, from the evidence of old trees growing on the rim; and it is thought to be less than five thousand years ago, from the fact that little erosion of the scattered blocks has taken place. Also the native Indians have a vague tradition of a fiery descent from heaven. Probably it may be dated between one and two thousand years ago.

\section{Mind as a Living Process}

THE second of the L. T. Hobhouse Memorial Trust lectures was given by Dr. Charles S. Myers on May 19, 1932, and has been published under the title of "The Absurdity of any Mind-Body Relation" (Oxford University Press. 2s. net). Dr. Myers maintains the view that any relation between mind and body is absurd because mental activity and living bodily activity are identical. The mechanical principles of the natural sciences are only an abstraction from the quasi-dual set of principles-direction and mechanism - that govern the entire un verse. Each is an ab. straction from the whole activity. Mind and life are identical properties of living matter, which differs from lifeless matter in its inherent, purposive, selfdirective, and finally purposeful struggle for existence. From this point of view then, the hypotheses of psycho-physical parallelism, of interactionism, and of either form of monism are untenable. Dr. Myers quotes with approval from Hobhouse to the effect that life arose not from dead elements, but from pre-material elements which also gave rise to inanimate matter, so that all life contains a germ of mind. Mind is thus to be regarded as the expression of the directive activity of living matter. This directive activity is to be regarded as the highest unitary activity of the nervous system : the lower directive activities may not always be in harmony with the highest and hence the mental conflicts, conscious and unconscious. Dr. Myers discusses the relation of the cognitive, affective and conative aspects of experience and the part played by instinct and intelligence. The point of view is most lucidly expressed and raises interesting questions for philosophy, psychology, biology and physical science. It is worthy of note that ancient and medieval thought realised the problem also, and that only from the context in many writings can one know whether the word 'anima' is to be translated life or mind.

\section{Origin of the Irish Flora and Fauna}

IN his presidential address delivered last November to the Royal Irish Academy, Dr. R. Lloyd Praeger returned to a subject which has occupied his attention for forty years-the problem of the Irish flora and fauna (Proc. Roy. Irish Acad., 41, 125). The problem has been much discussed, but always with an obscurity of background due to absence of fossil evidence which might give the clue to the routes and periods of past immigrations. In such circumstances conclusions assume a personal interpretation and Dr. Praeger's view is that much of the present flora and fauna reached Ireland over land-surfaces, either during inter-glacial (Aurignacian) times, or in the same way after the ice had finally passed away, or probably during both periods. Certain plants and animals found with these immigrants, including the American and probably the Lusitanian element, are older than these, and survived the main glaciation. These oldest elements migrated northward in pre-glacial times along the western European coast line, or eastward from America when the intervening barriers of sea were at least much less formidable than they are at present.

\section{Migration of Red Grouse}

THE University of Aberdeen inquiry into the move. ments of the red grouse would welcome the cooperation of owners or tenants of grouse-moors willing to ring young or adult birds during the present season. Rings, with instructions for their use, may be obtained from Prof. James Ritchie, Marischal College, Aberdeen. 